\title{
Erratum to: The Role of Religious Attitude Towards Religion Differences, Nationalism and Environment Concern
}

\author{
Muhammad Adnan*1, Budi Setyono ${ }^{1}$, Wahid Abdulrahman ${ }^{1}$ \\ ${ }^{1}$ Government Studies, Universitas Diponegoro, Indonesia
}

Original article: E3S Web of Conferences 73, 08024 (2018), https://doi.org/10.1051/e3sconf/20187308024

The Author of the article should be replaced by the following text:

Muhammad Adnan*1, Budi Setiyono ${ }^{1}$, Wahid Abdulrahman ${ }^{1}$

${ }^{1}$ Government Studies, Universitas Diponegoro, Indonesia 